\title{
CaRD Regimen
}

National Cancer Institute

\section{Source}

National Cancer Institute. CaRD Regimen. NCI Thesaurus. Code C160555.

A chemoimmunotherapy regimen consisting of carfilzomib, dexamethasone and rituximab that may be used in the treatment of Waldenstrom macroglobulinemia. 